\title{
How vegetables make the meal: their hedonic and heroic impact on perceptions of the meal and of the preparer
}

\author{
Brian Wansink, Mitsuru Shimizu and Adam Brumberg* \\ Warren Hall, Cornell University, Ithaca, NY 14853-7801, USA
}

Submitted 28 January 2012: Final revision received 18 September 2012: Accepted 21 September 2012: First published online 15 November 2012

\begin{abstract}
Objective: Although most parents know that vegetables are healthful, vegetables are served at only $23 \%$ of American dinners. If added nutrition is not a sufficient motivation, might a parent be more inspired to serve vegetables if doing so improved either the taste of the entrée or how loving and thoughtful the server would be perceived? The present paper details two studies which investigated whether serving vegetables changes the perception of the cook and the perception of an entrée's taste.

Design: In Study 1, people evaluated the personality of a cook who either did or did not include a vegetable in a family dinner. In Study 2, five different meals that either included or did not include a vegetable were rated in terms of the taste of the entrée and of the whole meal.

Setting: US-based online survey.

Subjects: American mothers ( $n 500$ ), ranging in age from 18 to 65 years (mean age 38.4 years), with at least two children under the age of 18 years living at home. Results: Serving vegetables improved taste expectations for the entrée as well as for the whole meal. Additionally, serving a vegetable with a meal also enhanced perceptions of the meal preparer. They were evaluated as being more thoughtful and attentive as well as less lazy, boring and self-absorbed.

Conclusions: These two studies show new hedonic and heroic motivations for serving vegetables: (i) they increase the hedonic appeal of the meal and (ii) they increase the heroic appeal of the cook. More vegetables are likely to be served with a meal if preparers know that the addition of vegetables makes them appear to be both a better cook and a better person.
\end{abstract}

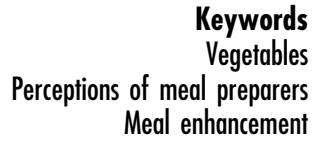

Most of the vegetables consumed in America - nearly $70 \%$ - are eaten during the evening meal. Unfortunately, vegetables are served with only $23 \%$ of all American dinners ${ }^{(1)}$. Although some suggest that the economic cost or the preparation time deters vegetable consumption ${ }^{(2)}$, there is still dramatic variation in serving frequency after controlling for income, work schedules and time availability $^{(3,4)}$. Part of the difference in how frequently a family serves vegetables may have to do with how vegetables are perceived in terms of what they contribute to the meal ${ }^{(5)}$. While they certainly contribute to making the meal healthier, how else might they contribute? Knowing how and why vegetable-serving and -eating parents and their children perceive vegetables as contributing to the meal - other than simply for their nutritional value - may hold the key to expanding vegetable intake.

With the exception of vegetarians or vegans, most people do not eat vegetables in isolation; they eat them as a complement to a meal ${ }^{(6)}$. While vegetables clearly add to the nutritional perceptions of a meal, what has been overlooked is how they might also influence other perceptions - the quality of the main dish (whatever is considered 'centre of the plate') or the characteristics of the cook ${ }^{(7-9)}$. The present paper examines two potentially important questions:

1. Does serving vegetables improve taste perceptions of the main course?

2. Does serving vegetables improve perceptions of the food preparer?

In addition, the research preliminarily explores how vegetable preferences vary across a child's age and gender and what vegetables are associated with the meals most commonly eaten by this sample.

\section{Background}

Vegetables play an important nutritional role in meals. What is less understood is how vegetables contribute to a meal in other ways that may be motivating to the person either preparing or eating it. For instance, how do vegetables influence hedonic expectations of the meal? Research on sensory-specific satiety has shown that a person is more 
likely to increase his/her intake of a food when it is paired with a complementary food that offers variety in taste and texture $^{(10)}$. Depending on preparation and the main course, vegetables could offer that textural contrast.

There are key differences, however, between people who like vegetables - vegetable-lovers - and people who are fruit-lovers, although they have similar sociodemographic traits and a similar interest in health and nutrition. A study of 1004 North Americans divided people into groups based on rating scales of how much they liked fruit and vegetables ${ }^{(11)}$. Wansink and Lee ${ }^{(11)}$ found that vegetable-loving cooks differed from fruit-loving cooks in both their preferences for other foods and their cooking habits. Vegetable-lovers tended to entertain guests, cook nutritious meals and try new recipes more frequently than fruit-lovers. The groups also had different food preferences. Vegetable-lovers ate spicy foods and drank wine with dinner more frequently, but ate desserts less frequently than fruit-lovers. A vegetable-lover's taste for savoury or bitter taste sensations was consistent with an attraction to spicy foods and tannic red wine, while a fruit-lover's sweet tooth was consistent with an attraction to desserts.

Importantly, these reported associations by vegetableloving cooks underscored key differences in their food preparation habits, their preferences and their personalities. If the image of a vegetable-preparing cook mirrors these reported differences in vegetable-loving cooks, it may be that a food preparer who simply adds a vegetable to a meal - even frozen or canned vegetables - may be perceived differently from one who does not. Building on prior findings that profiled the characteristics of vegetablelovers $^{(11)}$, a cook who serves vegetables with a meal may be perceived as a better cook. A more causal and conclusive investigation of this could be achieved by giving people descriptions of two identical people who differ only on whether they serve a vegetable for dinner and asking them to rate or describe the personality of that individual.

The inclusion of vegetables with a meal would in most cases enhance the perception that the meal is more nutritious and complete than one without vegetables. The focus of the present research is how the inclusion of vegetables influences taste expectations of the main course along with character inferences of the person preparing the meal. Based on the above findings related to expectations and character inferences, we expect the following.

$\mathrm{H}_{1}$ : Inclusion of vegetables with a meal will enhance sensory expectations of the main dish.

$\mathrm{H}_{2}$ : A person who serves a vegetable with dinner will be described with more positive traits and fewer negative traits than a person who does not serve a vegetable with dinner.

These hypotheses were investigated in a national study involving 500 American mothers with two or more children under the age of 18 years, by asking them to complete a questionnaire that included several sections.

\section{Methods}

A series of means-end laddering interviews ${ }^{(12)}$ were conducted ( $n$ 22) to identify a range of specific associations and beliefs people had concerning vegetables being served, the enjoyment of a meal, the quality of the meal experience and the perceptions of the person preparing the meal. To investigate the generalizability of such associations and beliefs about vegetables, a survey was designed to quantitatively test them with a nationwide sample of 500 adult women with at least two children under the age of 18 years living at home. Participants ranged in age from 18 to 65 years (mean age 38.4 years); $84 \cdot 8 \%$ were married; $10 \cdot 4 \%$ had completed high school and $28.3 \%$ some college, with the rest being college graduates. While there is diversity in this sample, the typical respondent reported having more education than would be expected from a random sample of American mothers.

The survey was conducted online by a national panel service (the MSR Group), which recruited e-Rewards panel members using a 'by invitation only' methodology and remunerated them with \$US 4.00 in e-Rewards currency. This quantitative survey took an average of $21 \mathrm{~min}$ to complete and was conducted on consecutive days from 1 September to 6 September, 2011. In recruiting the panel members, no mention was made that the study involved vegetables, food or family meals.

The survey involved four parts: (i) a projective scenario which involved describing a woman who either prepared or did not prepare vegetables with a family meal; (ii) a meal-rating study where respondents rated the quality and nutrition of four different meals which either contained or did not contain a serving of vegetables; (iii) basic ratings of how vegetables influence their perceptions of meals; and (iv) an open-ended self-report of their favourite vegetable and those of their oldest and youngest child.

To begin, a subset of respondents were asked to describe either a meal preparer who had served vegetables or a preparer who had not served vegetables with a meal. They read one of two versions of a scenario describing a working mother, her activities during the day and what she prepared for dinner. The only difference between the control scenario (Scenario 1) and treatment scenario (Scenario 2) was the inclusion of the sentence 'She also opens up a frozen bag of green beans and heats it up' after the sentence 'She heats up some leftover spaghetti from last night' in Scenario 2.

Valerie has been spending most of Thursday running errands and catching up on work around the house. She cooks four chicken breasts in a pan with salt and pepper. She heats up some leftover spaghetti from last night. As her husband and children arrive at the kitchen table, she serves the chicken and spaghetti along with rolls and butter. After dinner and after the cleanup, the kids go to their 
rooms to play. Valerie and her husband watch TV until it's time to put the children to bed.

Half of the respondents were randomly assigned to read one of the two scenarios. After reading their specific scenario, they were shown a list of twelve personality descriptors (attentive, caring, selfish, boring, lazy, familyoriented, good cook, self-absorbed, thoughtful, capable, loving and neglectful) and asked to choose the three descriptors that they thought best described the woman in the scenario.

The second portion of the study investigated how vegetables influenced perceptions of specific meals in terms of characteristics such as completeness, nutritional value, taste expectations, and how 'loving' the meal was. Respondents were asked to rate four meals on 9-point scales which referred to specific descriptions of the meal. These were measured on scales that ranged from 1 ('A not very...') to 9 ('A very...'). Each meal evaluation had an 'A' and a 'B' version; the A version of each meal contained a vegetable, the $B$ version did not. In each case, the main dish of each meal stayed constant with a vegetable being added in the case of two meals and the vegetable substituting for either a starchy side or a dessert in each of the other two meals. These meal evaluations followed a between-subjects design in which no respondent saw the same meal both with and without vegetables.

The third part of the study asked respondents a variety of questions regarding vegetables, such as 'I really love vegetables' on a 9-point scale ( $1=$ 'strongly disagree', $9=$ 'strongly agree'). They were then asked to report how many times they served a vegetable in the last ten dinners they had prepared at home. Finally, the survey asked specific attitude questions regarding the relationships between vegetables and meals, such as 'Vegetables make the meal more complete' on the same 9-point scale.

In the fourth part of the study, information regarding the favourite vegetables for the respondents' families was collected. Respondents were asked to describe their favourite vegetable dish, along with the preferred preparation. This was an open-ended question, with no limitations on responses. Respondents were also asked to list the five most frequently prepared meals in their homes, including all vegetables and side dishes.

The four parts of the study were sequenced in an order that provided the least bias to subsequent sections. Each participant completed the online survey of the randomly assigned first part, the randomly assigned second part, the third part and fourth part. Because the first two parts were randomized, the carry-over effects on the third and fourth parts were counterbalanced. We examined the effects of the conditions (i.e. two scenarios for Part 1, two versions for Part 2) by conducting a series of ANOVA.

The Cornell University Institutional Review Board conducted an ethical review of the experiment.

\section{Results}

\section{Vegetables and the perception of meals}

To indirectly compare how the inclusion of vegetables with a meal influences perceptions of the affective, sensory and nutritional perceptions of the meal, we first discuss the results from the section of the study where respondents were asked to rate either meals that contained vegetables or ones that did not. Across all four meals, the inclusion of a vegetable into a meal generally influenced the meal's affective perceptions ('loving meal') and nutritional perceptions ('complete meal', 'nutritious'), as well as sensory perceptions of both the complete meal ('tasty meal') and that of the main course ('tasty main course').

As Table 1 indicates, a one-way ANOVA revealed that evaluation scores of meal combinations were higher when vegetables were included with the meal (e.g. steak $7 \cdot 52 v$. steak with broccoli $8 \cdot 08 ; P<0 \cdot 001)$. The addition of a vegetable increased the average perception of most main dishes (e.g. baked chicken $7 \cdot 30 v$. chicken with green beans 7.74; $P<0 \cdot 001$ ). Perceptions of the meals as a whole increased in all cases for descriptors such as 'loving' (e.g. steak 7.00 $v$. steak with broccoli 7.92; $P<0 \cdot 001$ ) and 'complete meal' (e.g. burrito $6.48 v$. burrito with mixed vegetables $7 \cdot 74 ; \quad P<0 \cdot 001)$. Importantly, a multivariate ANOVA showed the results across four meals being significant for each five-question item $(P<0 \cdot 001)$.

One explanation of why vegetables may "make the meal' is that they might lead one to infer that the meal is being made with more effort or thought. An increased amount of effort and thought could suggest the meal is prepared with more consideration or 'love' and may be therefore tastier. To begin examining this, two of the meals with vegetables (burritos and baked chicken) included vegetables with meals as substitutes for other items (tortilla chips and ice cream) that would have also involved an extra step in the preparation or serving process (all $P<0 \cdot 01$ ). These significant results were as high as when vegetables were simply added to a twocourse meal, which was the case with both pasta with meatballs and steak with baked potato (all $P<0 \cdot 01$ ). This suggests that this impact of serving vegetables may have to do with the actual food (the vegetable) and not simply because it is an additional food.

While this first analysis involved indirect or inferred ratings of actual meal combinations, we also examined direct ratings of how vegetables influence the meals (Table 2). Regardless of a mother's affinity for vegetables, it is notable how high the mean ratings are for the influence of serving of vegetables on the rest of the meal. Nearly all mothers believed vegetables made the meal. The mean ratings for all of the items in Table 2 were significantly higher than the mid-point $(5 \cdot 0)$ on the 9-point scales. This included strongly agreeing to the affect-related associations that vegetables 'make the meal' $(P<0.001)$, 'make(s) the meal seem more special' $(P<0 \cdot 001)$ and 
Table 1 How vegetables influence taste perceptions of a mealt

\begin{tabular}{|c|c|c|c|c|c|c|}
\hline & \multicolumn{2}{|c|}{$\begin{array}{l}\text { Pasta with meatballs } \\
\text { and bread } \\
(n 250)\end{array}$} & \multicolumn{2}{|c|}{$\begin{array}{l}\text { Pasta with meatballs, bread } \\
\text { and zucchini } \\
(n 250)\end{array}$} & \multirow[b]{2}{*}{$F$ test } & \multirow[b]{2}{*}{$P$ value } \\
\hline & Mean & SD & Mean & SD & & \\
\hline Tasty main dish & $7 \cdot 60$ & $1 \cdot 39$ & $7 \cdot 85$ & $1 \cdot 29$ & $4 \cdot 16$ & 0.04 \\
\hline Complete meal & $6 \cdot 25$ & $2 \cdot 28$ & $8 \cdot 15$ & $1 \cdot 13$ & $137 \cdot 60$ & $<0.00$ \\
\hline Loving meal & $7 \cdot 40$ & $1 \cdot 47$ & $7 \cdot 91$ & $1 \cdot 30$ & $16 \cdot 49$ & $<0.00$ \\
\hline Tasty meal & $7 \cdot 58$ & $1 \cdot 41$ & $7 \cdot 86$ & $1 \cdot 38$ & $5 \cdot 11$ & 0.02 \\
\hline Nutritious & $6 \cdot 26$ & $1 \cdot 76$ & $7 \cdot 57$ & $1 \cdot 37$ & $86 \cdot 06$ & $<0.00$ \\
\hline
\end{tabular}

\begin{tabular}{|c|c|c|c|c|c|c|}
\hline & \multicolumn{2}{|c|}{$\begin{array}{l}\text { Steak and baked potato } \\
\qquad(n \text { 250) }\end{array}$} & \multicolumn{2}{|c|}{$\begin{array}{l}\text { Steak, baked potato and broccoli } \\
\qquad(n 250)\end{array}$} & & \\
\hline & Mean & SD & Mean & SD & & \\
\hline Tasty main dish & $7 \cdot 68$ & $1 \cdot 66$ & $7 \cdot 99$ & $1 \cdot 36$ & $5 \cdot 00$ & 0.03 \\
\hline Complete meal & $5 \cdot 40$ & $2 \cdot 54$ & $8 \cdot 05$ & $1 \cdot 56$ & $197 \cdot 99$ & $<0.001$ \\
\hline Loving meal & $7 \cdot 00$ & $1 \cdot 71$ & $7 \cdot 92$ & $1 \cdot 5$ & $40 \cdot 90$ & $<0.001$ \\
\hline Tasty meal & $7 \cdot 52$ & 1.63 & 8.08 & $1 \cdot 37$ & $17 \cdot 34$ & $<0.001$ \\
\hline Nutritious & $6 \cdot 13$ & $1 \cdot 78$ & $7 \cdot 80$ & $1 \cdot 43$ & $135 \cdot 12$ & $<0.001$ \\
\hline
\end{tabular}

\begin{tabular}{|c|c|c|c|c|c|c|}
\hline & \multicolumn{2}{|c|}{$\begin{array}{c}\text { Burritos, beans, rice and } \\
\text { tortilla chips } \\
\text { ( } n \text { 250) }\end{array}$} & \multicolumn{2}{|c|}{$\begin{array}{l}\text { Burritos, beans, rice and } \\
\text { mixed vegetables } \\
(n \text { 250) }\end{array}$} & & \\
\hline & Mean & SD & Mean & SD & & \\
\hline Tasty main dish & $7 \cdot 23$ & $1 \cdot 82$ & $7 \cdot 19$ & $1 \cdot 76$ & 0.05 & $0 \cdot 82$ \\
\hline Complete meal & $6 \cdot 48$ & $2 \cdot 38$ & $7 \cdot 74$ & $1 \cdot 55$ & $49 \cdot 71$ & $<0.001$ \\
\hline Loving meal & $6 \cdot 98$ & $1 \cdot 86$ & $7 \cdot 45$ & 1.71 & 8.69 & 0.03 \\
\hline Tasty meal & $7 \cdot 21$ & $1 \cdot 84$ & $7 \cdot 40$ & $1 \cdot 71$ & $1 \cdot 41$ & 0.24 \\
\hline Nutritious & $5 \cdot 98$ & $2 \cdot 08$ & $7 \cdot 41$ & $1 \cdot 42$ & $80 \cdot 67$ & $<0.001$ \\
\hline
\end{tabular}

\begin{tabular}{|c|c|c|c|c|c|c|}
\hline & \multicolumn{2}{|c|}{$\begin{array}{l}\text { Baked chicken with wild rice and ice } \\
\text { cream for dessert } \\
\qquad(n 250)\end{array}$} & \multicolumn{2}{|c|}{$\begin{array}{l}\text { Baked chicken with wild rice } \\
\text { and green beans } \\
(n \text { 250) }\end{array}$} & & \\
\hline & Mean & SD & Mean & SD & & \\
\hline Tasty main dish & $7 \cdot 30$ & 1.58 & $7 \cdot 74$ & $1 \cdot 47$ & $10 \cdot 22$ & 0.001 \\
\hline Complete meal & $5 \cdot 72$ & $2 \cdot 5$ & $8 \cdot 32$ & 1.00 & $231 \cdot 28$ & $<0.001$ \\
\hline Loving meal & $7 \cdot 08$ & $1 \cdot 68$ & $7 \cdot 95$ & $1 \cdot 31$ & $41 \cdot 17$ & $<0.001$ \\
\hline Tasty meal & $7 \cdot 25$ & $1 \cdot 58$ & $7 \cdot 70$ & $1 \cdot 53$ & $10 \cdot 51$ & 0.001 \\
\hline Nutritious & $6 \cdot 45$ & $1 \cdot 80$ & $8 \cdot 26$ & $1 \cdot 05$ & $187 \cdot 79$ & $<0.001$ \\
\hline
\end{tabular}

tRatings on 9-point scales which refer to specific descriptions of the meal and range from $1=$ 'not a very...' to $9=$ 'a very ...', assessing the impact of the addition of a vegetable on perceptions of meal combinations among 500 American mothers, with at least two children under the age of 18 years living at home, who participated in an online survey, September 2011.

Table 2 How vegetables influence hedonic taste perceptions of a mealt

\begin{tabular}{|c|c|c|c|c|c|c|c|c|}
\hline & \multicolumn{2}{|c|}{ Total } & \multicolumn{2}{|c|}{$\begin{array}{l}\text { Higher affinity for } \\
\text { vegetables } \\
(n 250)\end{array}$} & \multicolumn{2}{|c|}{$\begin{array}{l}\text { Lower affinity for } \\
\text { vegetables } \\
(n 250)\end{array}$} & \multirow[b]{2}{*}{$F$ value } & \multirow[b]{2}{*}{$P$ value } \\
\hline & Mean & SD & Mean & SD & Mean & SD & & \\
\hline Vegetables make the meal & $6 \cdot 84$ & 1.99 & $7 \cdot 09$ & $2 \cdot 05$ & $6 \cdot 69$ & 1.95 & $4 \cdot 63^{*}$ & 0.032 \\
\hline Vegetables make the meal more complete & $8 \cdot 30$ & $1 \cdot 32$ & $8 \cdot 45$ & $1 \cdot 17$ & $8 \cdot 21$ & $1 \cdot 39$ & $4 \cdot 05^{\star}$ & 0.045 \\
\hline A vegetable makes the meal seem more special & $6 \cdot 72$ & $2 \cdot 07$ & 6.95 & $2 \cdot 26$ & $6 \cdot 58$ & 1.94 & $3 \cdot 80$ & 0.052 \\
\hline A vegetable makes the meal healthier & $8 \cdot 43$ & $1 \cdot 19$ & 8.52 & $1 \cdot 12$ & $8 \cdot 37$ & $1 \cdot 23$ & 1.91 & $0 \cdot 167$ \\
\hline A vegetable makes beef taste better & $6 \cdot 37$ & $2 \cdot 21$ & $6 \cdot 63$ & $2 \cdot 27$ & $6 \cdot 21$ & $2 \cdot 16$ & $4 \cdot 28^{*}$ & 0.039 \\
\hline A vegetable makes chicken taste better & $6 \cdot 51$ & $2 \cdot 17$ & $6 \cdot 82$ & $2 \cdot 13$ & $6 \cdot 32$ & $2 \cdot 17$ & $6 \cdot 18^{*}$ & 0.013 \\
\hline A vegetable makes pork taste better & $6 \cdot 07$ & $2 \cdot 29$ & $6 \cdot 38$ & $2 \cdot 38$ & $5 \cdot 89$ & $2 \cdot 21$ & $5 \cdot 49^{\star}$ & 0.020 \\
\hline A vegetable makes fish taste better & $6 \cdot 06$ & $2 \cdot 43$ & $6 \cdot 49$ & $2 \cdot 40$ & $5 \cdot 82$ & $2 \cdot 42$ & $9 \cdot 01^{\star \star}$ & 0.003 \\
\hline A vegetable makes the meal feel more 'family-like' & $7 \cdot 19$ & $1 \cdot 95$ & $7 \cdot 34$ & $2 \cdot 09$ & $7 \cdot 10$ & $1 \cdot 86$ & $1 \cdot 77$ & $0 \cdot 184$ \\
\hline
\end{tabular}

${ }^{*} P<0.05,{ }^{* *} P<0.01$.

tRatings on a 9-point scale, from $1=$ 'strongly disagree' to $9=$ 'strongly agree', assessing the impact of the addition of a vegetable on hedonic taste perceptions of a meal among 500 American mothers, with at least two children under the age of 18 years living at home, who participated in an online survey, September 2011. A median split on the mother's general attitude towards vegetables was used to determine whether she had a lower or higher affinity for vegetables. 
Table 3 How serving vegetables changes perceptions of the cookt

\begin{tabular}{|c|c|c|c|c|}
\hline & $\begin{array}{l}\text { Scenario in which a cook does } \\
\text { not serve a vegetable with dinner } \\
(\text { ( } 141)\end{array}$ & $\begin{array}{l}\text { Scenario in which a cook serves } \\
\text { a vegetable with dinner } \\
\text { ( } n \text { 120) }\end{array}$ & $F$ value & $P$ value \\
\hline Thoughtful & $15 \cdot 6$ & $25 \cdot 8$ & $4 \cdot 229^{*}$ & 0.04 \\
\hline Attentive & $14 \cdot 9$ & $29 \cdot 2$ & $4 \cdot 017^{*}$ & 0.05 \\
\hline Family-oriented & $65 \cdot 3$ & $73 \cdot 3$ & $1 \cdot 980$ & $0 \cdot 16$ \\
\hline Capable & $58 \cdot 9$ & $65 \cdot 0$ & $1 \cdot 028$ & 0.31 \\
\hline Good cook & $11 \cdot 4$ & $8 \cdot 3$ & 0.653 & 0.42 \\
\hline Caring & $47 \cdot 5$ & $42 \cdot 5$ & 0.656 & 0.42 \\
\hline Loving & $22 \cdot 0$ & $22 \cdot 5$ & 0.010 & 0.92 \\
\hline Neglectful & $9 \cdot 2$ & $6 \cdot 7$ & 0.568 & 0.45 \\
\hline Selfish & $6 \cdot 4$ & $4 \cdot 2$ & 0.624 & 0.43 \\
\hline Boring & $27 \cdot 7$ & $15 \cdot 8$ & $5 \cdot 312^{*}$ & 0.02 \\
\hline Self-absorbed & $7 \cdot 8$ & $1 \cdot 7$ & $5 \cdot 219^{*}$ & 0.02 \\
\hline Lazy & $13 \cdot 5$ & $5 \cdot 0$ & $5 \cdot 447^{*}$ & 0.02 \\
\hline
\end{tabular}

${ }^{*} P<0.05$.

†The percentage who believed the attribute was one of three that best described the cook among 500 American mothers, with at least two children under the age of 18 years living at home, who participated in an online survey, September 2011.

'make(s) the meal feel more "family-like"' $(P<0 \cdot 001)$, as well as to the more health-related associations such as vegetables 'make the meal more complete' $(P<0 \cdot 001)$ and 'make(s) the meal healthier' $(P<0 \cdot 001)$. Additionally, respondents generally agreed that the addition of vegetables make the main course taste better. They were generally in strong agreement that a vegetable makes 'beef taste better' (mean $=6 \cdot 37$ ), 'chicken taste better' (mean $=6.51)$, 'pork taste better' (mean $=6 \cdot 07)$ and 'fish taste better' (mean $=6 \cdot 06$ ).

To understand how individual differences might explain some of the variation in responses, a mean split was used to divide the mothers into two groups based on how they responded to the statement 'I really love vegetables'. Unsurprisingly, self-identified vegetable-lovers were more extreme in the positive affect they associated with meals containing vegetables (see Table 2). That is, vegetable-lovers were more likely to indicate that vegetables 'make the meal' (7.09 v. 6.69; $P=0.032)$, 'make it more complete' $(8.45 v .8 \cdot 21 ; P=0 \cdot 045)$ and 'make(s) the meal seem more special' $(6 \cdot 95 v \cdot 6 \cdot 58 ; P=0 \cdot 052)$. Consistent with the hypothesis that vegetables make the main course taste better than it otherwise would, vegetable-lovers also believed the inclusion of vegetables in a meal made the entrée taste better regardless of whether that entrée was beef $(6.63 v .6 \cdot 21 ; P=0 \cdot 039)$, chicken $(6.82 v .6 \cdot 32$; $P=0 \cdot 013)$, pork $(6 \cdot 38 v .5 \cdot 89 ; P=0 \cdot 02)$ or fish (6.49v. 5.82; $P=0 \cdot 003)$. While these analyses were based on the extent to which people claimed to love vegetables, similar results were found when they were divided into two groups based on how frequently they served vegetables (all $P<0 \cdot 05$ ).

It is not surprising that vegetable-loving mothers believe that vegetables 'make the meal' more than those who love them less. What is notable is how high the mean ratings were for both groups.

\section{Vegetables and the perception of meal preparers}

In addition to influencing the perceived quality of the meal, it was also believed that the inclusion of vegetables would influence perceptions of the meal preparer. Recall that the first part of the study - before there had been any mention of vegetables - had participants read one of two fictional scenarios. The only point of difference between the two scenarios is that during the evening meal, one scenario included a vegetable with the quick meal made for the family. After reading one of the two scenarios, each person selected three qualities that best represented Valerie, the preparer. A series of ANOVA revealed significant differences in responses between those who read the scenario which included vegetables and those who did not. As shown in Table 3, the former were more likely to describe her as thoughtful $(25 \cdot 8 \% v \cdot 15 \cdot 6 \% ; P=0 \cdot 04)$ or attentive $(29 \cdot 2 \% v .14 .9 \% ; P=0.05)$ and less likely to describe her as lazy $(5 \cdot 0 \% v \cdot 13 \cdot 5 \%, P=0 \cdot 02)$, self-absorbed $(1 \cdot 7 \% v \cdot 7 \cdot 8 \%, P=0 \cdot 02)$ or boring $(15 \cdot 8 \% v \cdot 27 \cdot 7 \%$; $P=0 \cdot 02)$. Although not all of the other seven descriptors were statistically significant, all were directional, which is noteworthy given that respondents were limited to choosing only three of twelve possible descriptors.

To determine how the inclusion of a vegetable influences perceptions of the cook, the descriptors were aggregated into two groups: positive (attentive, caring, family-oriented, good cook, thoughtful, capable, loving) or negative (selfish, boring, lazy, self-absorbed, neglectful). The directionality seen in each individual descriptor was repeated in the groups. When the mother was described as having served vegetables, the average percentage who used positive attributes to describe her was significantly higher $(P=0 \cdot 003)$, and the average percentage using negative attributes was significantly lower $(P=0 \cdot 013)$.

\section{Vegetable preferences}

While parents commonly contend that their children dislike vegetables, this is inconsistent with the present results. An average of $70 \cdot 2 \%$ of mothers easily recalled what they believed to be the favourite vegetable of their 
Table 4 Which vegetables make the mealt

\begin{tabular}{|c|c|c|c|c|c|c|}
\hline & $\begin{array}{l}\text { Mother's } \\
\text { favourite } \\
(n 500)\end{array}$ & $\begin{array}{l}\text { Oldest male } \\
\text { child's favourite } \\
(n 278)\end{array}$ & $\begin{array}{l}\text { Oldest female } \\
\text { child's favourite } \\
\quad(n 222)\end{array}$ & $\begin{array}{c}\text { Youngest male } \\
\text { child's favourite } \\
(n 346)\end{array}$ & $\begin{array}{l}\text { Youngest female } \\
\text { child's favourite } \\
\text { (n } 346)\end{array}$ & $\begin{array}{l}\text { Served with family's } \\
\text { top three meals } \\
(n 500)\end{array}$ \\
\hline Broccoli & $24 \cdot 4$ & $18 \cdot 3$ & $20 \cdot 3$ & $12 \cdot 2$ & $17 \cdot 0$ & $75 \cdot 8$ \\
\hline Green beans & $16 \cdot 6$ & $10 \cdot 4$ & $7 \cdot 7$ & $8 \cdot 1$ & $10 \cdot 5$ & $52 \cdot 9$ \\
\hline Carrots & $12 \cdot 6$ & $12 \cdot 6$ & $12 \cdot 6$ & $14 \cdot 0$ & $12 \cdot 7$ & $39 \cdot 8$ \\
\hline Corn & $8 \cdot 2$ & $18 \cdot 0$ & $15 \cdot 8$ & $22 \cdot 5$ & $14 \cdot 8$ & $23 \cdot 8$ \\
\hline Green pepper & $8 \cdot 2$ & $2 \cdot 2$ & $2 \cdot 7$ & 0.4 & $2 \cdot 6$ & $24 \cdot 4$ \\
\hline Zucchini/squash & $8 . \overline{0}$ & $1 \cdot 4$ & 0.5 & $1 \cdot 1$ & $2 \cdot 6$ & $26 \cdot 6$ \\
\hline Potato & $7 \cdot 6$ & $7 \cdot 6$ & $7 \cdot 2$ & $5 \cdot 5$ & $4 \cdot 8$ & $22 \cdot 4$ \\
\hline Asparagus & $6 \cdot 6$ & $0 \cdot 7$ & $1 \cdot 8$ & 1.5 & 3.9 & $25 \cdot 3$ \\
\hline Tomatoes & $6 \cdot 0$ & $6 \cdot 1$ & $8 \cdot 1$ & $4 \cdot 8$ & $5 \cdot 2$ & $34 \cdot 8$ \\
\hline Cauliflower & $6 \cdot 0$ & $1 \cdot 1$ & $3 \cdot 6$ & $1 \cdot 5$ & 0.4 & $16 \cdot 3$ \\
\hline Mixed veggies & $4 \cdot 8$ & $2 \cdot 5$ & $3 \cdot 2$ & $1 \cdot 8$ & $3 \cdot 1$ & $12 \cdot 1$ \\
\hline Sweet potato & $1 \cdot 0$ & $2 \cdot 2$ & $2 \cdot 3$ & $2 \cdot 2$ & $3 \cdot 1$ & $2 \cdot 0$ \\
\hline
\end{tabular}

tThe percentage of verbatim responses for an open-ended question among 500 American mothers, with at least two children under the age of 18 years living at home, who participated in an online survey, September 2011. Some respondents chose not to answer all questions.

oldest child (72.5\%) and the favourite vegetable of their youngest child $(68 \cdot 0 \%)$. The wide variety of vegetables that were mentioned in the present study suggested a greater acceptance for vegetables than might have been expected. Of the top twelve vegetables mentioned in open-ended responses in the study, Table 4 indicates how frequently they were noted as a favourite among the mothers as well as how frequently they mentioned them as being the favourite of their oldest or youngest child. For instance, broccoli is a favourite vegetable across many of the demographics, except for young males who prefer both corn $(22 \cdot 5 \%)$ and carrots $(14 \cdot 0 \%)$ to broccoli $(12 \cdot 2 \%)$.

To determine the range of meals that are prepared in homes and the types of vegetables served with them, mothers were asked to note the three meals they most frequently prepared in their homes and the vegetables they most commonly served. Both the meals and the vegetables were coded, and the frequency that each of the twelve different vegetables was mentioned in one of a person's three top meals is indicated in the last column of Table 4. A notable finding is that the four vegetables that most frequently appeared in these favourite meals were broccoli $(75 \cdot 8 \%)$, green beans $(52 \cdot 9 \%)$, carrots $(39 \cdot 8 \%)$ and tomatoes $(34 \cdot 8 \%)$. Interestingly, while tomatoes were frequently found in meals, it was seldom selected as a favourite vegetable. While this could be because some people classified it as a fruit and not a vegetable, it more likely indicates that some vegetables take more of a side or 'ingredient' role than others. They might be more commonly found in a sauce than as a stand-alone component.

\section{Discussion}

For the majority of people, with the exception of vegetarians or vegans, it is unlikely that vegetables will be the 'hero' of a meal. For most, vegetables may not be as appealing when considered abstractly or when viewed in isolation as they are when they are complementing a main course. What the present research shows, however, is that vegetables can play a potentially powerful role in increasing the overall enjoyment of a meal. Tables 1 and 2 clearly show that vegetables add to a meal across a variety of dimensions beyond what would be expected merely from a nutritional standpoint.

One potential explanation is simply that the vegetable signifies additional work and time put into a meal, which translates into notions of loving, caring or attentiveness. However, while this was significant for vegetables, it was not significant for the more hedonic substitutes such as chips.

This concept is supported by the results of the evaluation task involving perceptions of Valerie. Given that the significant descriptors (thoughtful and attentive $v$. lazy and self-absorbed) are impacted either positively (thoughtful and attentive) or negatively (lazy and selfabsorbed) by the addition of frozen green beans to the meal, a connection between being a caring meal preparer and serving vegetables is suggested.

An average of $70 \cdot 2 \%$ of mothers were quick to recall what they believed to be their oldest child's (72.5\%) and youngest child's $(68 \cdot 0 \%)$ favourite vegetable. This means that the majority of children had a favourite vegetable but that it changed with the age of the child. Further evidence is found in the variety of the vegetables served with the most popular meals. While broccoli is reported as the most served vegetable, half of the remaining eleven vegetables are served with over $25 \%$ of the top meals.

While the present research offers new insights into how the serving of vegetables has a broad impact on the perceptions of main dishes and food preparation, it has limitations. First, the self-reporting of preferences and the bias that incurs is present in the study, particularly when parents were asked the vegetable preferences of their children. Second, it is important to underscore that the inclusion of vegetables in a meal made people anticipate that the main course would taste better. They did not actually consume it. Further research should examine if vegetables actually do improve taste ratings of the main 
course and not simply people's perception of how they think it will taste.

\section{Implications}

Unlike most vegetable research, the present study did not focus on the nutritional aspects of the meal. Instead, it focused on two overlooked key factors motivating the preparation of vegetables: perceptions related to the main course and perceptions related to the food preparer. In short, vegetables make people more positive towards both the main course and the cook. If a parent believes that adding a vegetable gives his/her family a better perception of the cook and what is cooked, it should be a powerful motivator to serve vegetables more often, certainly more often than during only $23 \%$ of all dinners.

The research suggests several motivations and useful courses of action for increasing the serving of vegetables in certain households. From the point of view of increasing vegetable serving and consumption, promoting vegetables may best be accomplished not in isolation but as a complement to a main course or meal. This approach is promising, given the clear implication that adding a vegetable to a meal enhances that meal in a variety of ways. This may be an especially good tactic in families where the nutritional gatekeeper is not a 'veggie lover'. Characterizing vegetables not merely as 'good for you' or as part of a balanced meal but as a flavour enhancer could motivate a meal preparer. Even those who do not particularly like vegetables appear to view those who serve them in an aspirational light. They rate them as fulfilling goals of caring and attentiveness, despite the fact that they do not themselves have a preference for them. Emphasizing that vegetables have the perceived ability to make the server a 'hero' may result in increased serving frequency.

The broad range of vegetables served in multiple meal combinations indicates that an increased variety of vegetables served to children, especially when paired with popular entrées, can be an effective method for increasing consumption. It is also clear that a parent should consider changing what vegetables are served to children as they get older as this will help to respond to their changing tastes as they mature.

The 2010 US Dietary Guidelines suggests that Americans make half of their plate fruits and vegetables. Both of these foods are currently under-consumed. If full servings of vegetables are present in only $23 \%$ of all family dinners, increasing their presence is a precondition to increasing their consumption. Providing a new motivation for meal preparers to serve vegetables is needed. These two studies show new hedonic and heroic motivations for serving vegetables: (i) they increase the hedonic appeal of the meal; and (ii) they increase the heroic aspect of the cook. If the nutritional impact of adding vegetables to a meal is not enough motivation for a cook to do so, perhaps these hedonic and heroic appeals will help.

\section{Acknowledgements}

Sources of funding: The research reported in the present paper was funded in part by Pinnacle Foods. Conflicts of interest: The authors have no additional conflicts of interest. Authors' contributions: B.W. contributed to conception and design of the experiment, analysis and interpretation of the data, drafting and revision of the article, and final approval of the version to be published. M.S. contributed to analysis and interpretation of the data, and drafting and revision of the article. A.B. contributed to conception and design of the experiment, analysis and interpretation of the data, and drafting and revision of the article.

\section{References}

1. Satia J, Kristal A, Patterson R et al. (2002) Psychosocial factors and dietary habits associated with vegetable intake. Nutrition 18, 247-254.

2. Trudeau E, Kristal AR, Li S et al. (1998) Demographic and psychosocial predictors of fruit and vegetable intakes differ: implications for dietary intervention. $J$ Am Diet Assoc 98, 1412-1417.

3. Tohill B, Seymour J, Serdula M et al. (2004) What epidemiologic studies tell us about the relationship between fruit and vegetable consumption and body weight. Nutr Rev 62, 365-370.

4. Wansink B (2003) Profiling nutritional gatekeepers: three methods for differentiating influential cooks. Food Qual Prefer 14, 289-297.

5. Birch LL (1999) Development of food preferences. Annu Rev Nutr 19, 41-62.

6. Brug J, Lechner L \& De Vries H (1995) Psychosocial determinants of fruit and vegetable consumption. Appetite 25, 285-296.

7. Wansink B, Bascoul G \& Chen G (2006) The sweet tooth hypothesis: how fruit consumption relates to snack consumption. Appetite 47, 107-110.

8. Thompson RL, Margetts BM, Speller VM et al. (1999) The Health Education Authority's Health and Lifestyle Survey 1993: who are the low fruit and vegetable consumers? J Epidemiol Community Health 53, 294-299.

9. Laforge RG, Greene GW \& Prochaska JO (1994) Psychosocial factors influencing low fruit and vegetable consumption. J Behav Med 17, 361-374.

10. Raudenbush B, Van Der Klaauw NJ \& Frank F (1995) The contribution of psychological and sensory factors to food preference patterns as measured by the Food Attitudes Survey. Appetite 25, 1-15.

11. Wansink B \& Lee K (2004) Cooking habits provide a key to 5 a day success. J Am Diet Assoc 104, 1648-1650.

12. Reynolds T \& Gutman J (1988) Laddering theory, method, analysis, and interpretation. $J$ Advertising Res $\mathbf{2 8}$, $11-31$. 